\title{
Induced overexpression of CD44 associated with resistance to apoptosis on DNA damage response in human head and neck squamous cell carcinoma cells
}

\author{
EMIKA OHKOSHI $^{1}$ and NAOKI UMEMURA ${ }^{2}$ \\ ${ }^{1}$ Department of Natural and Medicinal Chemistry, Faculty of Pharmaceutical Sciences Aomori University, Aomori, \\ Aomori 030-0943; ${ }^{2}$ Department of Oral Biochemistry, Asahi University School of Dentistry, Gifu 501-0296, Japan
}

Received October 14, 2016; Accepted November 28, 2016

DOI: $10.3892 /$ ijo.2016.3821

\begin{abstract}
CD44 is a marker of cancer stem cells in head and neck squamous cell carcinoma, and CD44 expression is related to prognosis in cancer patients. We examined whether herbal medicine components affect CD44 expression and induce cancer cell apoptosis. Baicalin enhanced apoptosis with no effect on CD44 levels, while baicalein did not enhance apoptosis and upregulated CD44 in head and neck squamous cell carcinoma. Furthermore, baicalein induced phosphorylation of CHK1, as a marker of DNA damage response to S-to-G2/M phase arrest. Our results clearly demonstrated that baicalein enhanced expression of CD44 and accordingly enhanced the DNA damage response. These data suggest that induction of CD44 inhibited cancer cell induction of apoptosis by increasing the DNA damage response. Together, our findings suggest that CD44 expression in head and neck squamous cell carcinoma plays a role in enhancing the DNA damage response.
\end{abstract}

\section{Introduction}

Many studies have demonstrated that a variety of human malignancies, including head and neck squamous cell carcinoma (HNSCC), contain subpopulations of cells called cancer stem-like cells (CSCs) that exhibit stem cell-like properties, such as self-renewal and tumor-initiating capabilities $(1,2)$. CSCs can lead to disease progression by giving rise to new tumors despite therapeutic intervention. The resistance of CSCs to conventional chemoradiotherapy may involve enhanced DNA damage repair pathways and alterations in cell cycle kinetics (3).

Correspondence to: Dr Naoki Umemura, Department of Oral Biochemistry, Asahi University School of Dentistry, 1851 Hozumi, Gifu 501-0296, Japan

E-mail: umemura@dent.asahi-u.ac.jp

Key words: cancer stem cells, cell cycle arrest, Chinese herbal drugs, baicalein, baicalin, herbal preparations
CD44 has been recently recognized as one of the cell surface markers associated with CSCs in $\operatorname{HNSCC}(4,5)$. A previous study showed that a CD $44^{+}$cell subset in HNSCC was predominantly in $\mathrm{G} 2 / \mathrm{M}$ phase compared with the $\mathrm{CD} 44^{-}$ cell subset associated with resistance to apoptosis $(6,7)$. The upregulation of CD44 serves as a survival mechanism, allowing cells to escape apoptotic cell death in response to DNA damage repair in HNSCC. Although the nature of CSCs is still controversial, CD44-expressing subfractions of many human carcinomas are highly malignant and share common properties with CSCs $(8,9)$.

Scutellaria root is a common component of many preparations in traditional Chinese medicine (10). It is a multi-purpose treatment, for inflammation, hypertension, cardiovascular diseases, and bacterial and viral infections. Chinese herbal medicine is a mixture of many herbs following the theory of traditional Chinese medicine $(11,12)$. Among these herbs, the main drugs that contain Scutellaria root are Shosaikoto (Xiao-Chai-Hu-Tang) (13), Daisaikoto (Da-ChaiHu-Tang) (14), Saireito (Chai-Ling-Tang) (15), Saikokeishito (Chai-Hu-Gui-Zhi-Tang) (16), and Saikokaryukotsuboreito (Chai-Hu-Jia-Long-Gu-Mu-Li-Tang) (17). The medicinal effects of these medicines improve gastrointestinal, liver and breathing responses, targets immune function, and relieves inflammation (18). The medicines use different diagnostic depending on traditional Chinese medicine. Some research reports have claimed that the herbal medicines that contain Scutellaria root can inhibit cancer $(10,19,20)$. However, the effects of traditional medicines on CSCs are unclear.

Here, we explored the Scutellaria root ingredient of herbal medicine and its effects on CSCs of HNSCC. We analyzed its effects on CD44, a marker of CSCs, and on the cell cycle in HNSCC.

\section{Materials and methods}

Reagents and antibodies. Dimethyl sulfoxide (DMSO), sodium dodecyl sulfate (SDS), baicalin, baicalein, and cisplatin were purchased from Wako Pure Chemical Industries, Ltd. (Osaka, Japan). Dulbecco's modified Eagle's medium (DMEM) was purchased from Invitrogen (Carlsbad, CA, USA), and fetal bovine serum (FBS) was purchased from Nichirei Bioscience 
(Tokyo, Japan). Primary antibodies against CD44 and cPARP were purchased from Cell Signaling Technology (Danvers, MA, USA), and primary antibodies against phospho-CHK1 (S301) and $\beta$-actin were purchased from Sigma-Aldrich (St. Louis, MO, USA). The horseradish peroxidase-conjugated secondary anti-mouse immunoglobulin $\mathrm{G}(\mathrm{IgG})$ and antirabbit $\mathrm{IgG}$ antibodies were purchased from Santa Cruz Biotechnology, Inc. (Santa Cruz, CA, USA). The protein assay kit was purchased from Bio-Rad (Herndon, VA, USA). Liquid chromatography-grade acetonitrile, acetic acid, ethyl acetate, methanol, 1-butanol, 2-propanol, baicalein, baicalin, and trifluoroacetic acid [for use in the high-performance liquid chromatography (HPLC) experiments described below] were purchased from Wako Pure Chemical Industries, Ltd. Milli-Q plus water (Millipore, Bedford, MA, USA) was used in the present study. All other chemicals were purchased from Wako Pure Chemical Industries, Ltd., except where otherwise noted.

Plant materials. Dried powders of herbal medicine [Shosaikoto (Xiao-Chai-Hu-Tang) (21), Daisaikoto (Da-Chai-Hu-Tang) (22), Saireito (Chai-Ling-Tang) (23), Saikokeishito (ChaiHu-Gui-Zhi-Tang) (24), and Saikokaryukotsuboreito (Chai-Hu-Jia-Long-Gu-Mu-Li-Tang) (25)] and Scutellaria root extract were supplied by Tsumura Co., Ltd. (Tokyo, Japan). The herbal medicines contained several dried herbs in fixed proportions, as standardized by the Health, Labour and Welfare Ministry of Japan (Table I). The quality of each crude herb was tested in accordance with the guidelines set out by the pharmacopoeia of Japan. The root drugs were extracted by boiling, and the decoctions were lyophilized and stored at room temperature under desiccated conditions until use. The dried powders were reconstituted and employed as hot water extracts.

Cell culture. The HNSCC cell lines HSC-2 and HSC-3 were obtained from Riken Cell Bank (Ibaraki, Japan). The human immortalized non-tumorigenic keratinocyte cell line HaCaT was supplied by DKFZ (Heidelberg, Germany). Cells were cultured in Dulbecco's modified Eagle's medium (DMEM; Life Technologies Japan Ltd.) supplemented with 10\% FBS (Life Technologies Japan Ltd.) and antibiotics [penicillin $(100 \mathrm{U} / \mathrm{ml})$, streptomycin $(100 \mu \mathrm{g} / \mathrm{ml})$ and amphotericin B $(25 \mu \mathrm{g} / \mathrm{ml})]$ at $37^{\circ} \mathrm{C}$ in a humidified atmosphere containing $5 \% \mathrm{CO}_{2}$.

Cell viability assay. Baicalin and baicalein stock solutions were prepared in DMSO and added to the cultured HSC-2, HSC-3, and $\mathrm{HaCaT}$ cells in DMEM/10\% FBS to achieve the indicated concentrations. The cells were incubated for the indicated periods of time. Cell viability was determined by performing 3-(4,5-dimethylthiazol-2-yl)-2,5-diphenyltetrazolium bromide (MTT) colorimetric assays with the Cell Proliferation kit I (Roche Diagnostics GmbH, Mannheim, Germany) according to the manufacturer's instructions. The number of viable cells was assessed by measuring the absorbance of the formazan crystals at $595 \mathrm{~nm}$ with a MultiSkan JX microplate reader and Ascent software (Thermo Labsystems, Vantaa, Finland). All data are presented as the mean \pm standard deviation (SD) of at least three independent experiments.
Quantitative analysis of baicalin and baicalein contents in five herbal medicines. A Jasco HPLC system (Jasco, Inc., Tokyo, Japan), equipped with a pump and a spectrophotometer suitable for ultraviolet (UV)/visible light detection, was used to generate a chromatogram at $277 \mathrm{~nm}$ for the analysis of baicalin and baicalein contents in Shosaikoto, Daisaikoto, Saireito, Saikokeishito, and Saikokaryukotsuboreito. Chromatographic conditions were adapted from a previous report (26), with the following minor modifications. The experiment used a Mightysil RP-18 GP 150-4.6 column (Kanto Corp., Tokyo, Japan). Eluent A corresponded to $0.05 \%$ trifluoroacetic acid (v/v), and eluent B corresponded to acetonitrile. The linear gradient of A to B consisted of $80-40 \%$ eluent A for $0-40 \mathrm{~min}$, followed by $40-0 \%$ eluent $\mathrm{A}$ for $40-50 \mathrm{~min}$. The flow rate was $1.0 \mathrm{ml} / \mathrm{min}$ at ambient temperature, and the injection volume was $10 \mu 1$. Calibration curves were obtained from plots of the peak area versus the concentration of the baicalin or the baicalein calibration standard $(10-250 \mu \mathrm{g} / \mathrm{ml}, \mathrm{r}=0.999)$. All experiments were conducted in triplicate.

CD44 knockdown. CD44 knockdown was achieved using short hairpin RNA (shRNA) retrovirus particles. Oligonucleotides encoding shRNAs that target standard exons in CD44 mRNA (shCD44) were cloned into the plasmid vector pSINsi-hU6-Neo (Takara Bio Inc. Shiga, Japan). The DNA sequences corresponding to the CD44 and control shRNAs were 5'-GTGTACATCCTCACATCCA-3' (shCD44) and 5'-TCTTAATCGCGTATAAGGC-3' (shCtrl), respectively. The plasmids were transfected into HSC-3 cells using Lipofectamine RNAiMAX (Invitrogen) according to the manufacturer's instructions, and the cells were cultured for 2 weeks in the presence of neomycin $(0.6 \mathrm{mg} / \mathrm{ml}$; Roche Diagnostics, IN, USA). CD44 knockdown in HSC-3 cells was confirmed by immunoblotting and immunofluorescence.

Cell cycle analysis. HSC-3 cells or shCD44 HSC-3 cells were treated with $100 \mu \mathrm{M}$ baicalin or baicalein for $48 \mathrm{~h}$ at $37^{\circ} \mathrm{C}$. Appropriate controls were also set up. Nuclei were labeled with propidium iodide (PI) (BD Pharmingen, BD BioSciences, San Jose, CA, USA), and the DNA contents of the PI-labeled nuclei were measured via flow cytometry according to the manufacturer's instructions (BD Pharmingen). Data acquisition and analysis were performed using a Beckman Coulter EPICS Altra Flow Cytometer and Expo3 v1.2B analysis software (Beckman Coulter, Brea, CA, USA).

Immunoblot analysis. HCS-3 cells were treated with DMSO, baicalin and baicalein $(100 \mu \mathrm{M})$, cisplatin $(10 \mu \mathrm{M})$, five herbal medicines $(50 \mu \mathrm{g} / \mathrm{ml})$, or Scutellaria root extract $(50 \mu \mathrm{g} / \mathrm{ml})$. Cells were scraped with a rubber policeman and collected in 10X cell lysis buffer (Cell Signaling Technology, Beverly, MA, USA). A solution containing phenylmethanesulfonyl fluoride $(1 \mathrm{mM})$ plus one tablet of protease inhibitor cocktail (Complete, EDTA-free; Roche Diagnostics GmbH, Mannheim, Germany) was added to each cell lysate. Protein contents in the lysates were assayed, and equal amounts of protein for each sample were subjected to SDS-polyacrylamide gel electrophoresis, followed by immunoblotting with primary antibodies against anti-CD44 mouse monoclonal antibody, anti-cleaved PARP rabbit monoclonal antibody (all from Cell 
Table I. Crude herbal constituents (percentages) and clinical indications of five herbal medicines.

\begin{tabular}{|c|c|c|c|c|c|}
\hline $\begin{array}{l}\text { Sample } \\
\text { Crude herb }\end{array}$ & $\begin{array}{c}\text { Shosaikoto } \\
\text { Xiao-Chai-Hu-Tang }\end{array}$ & $\begin{array}{c}\text { Daisaikoto } \\
\text { Da-Chai-Hu-Tang }\end{array}$ & $\begin{array}{c}\text { Saireito } \\
\text { Chai-Ling-Tang }\end{array}$ & $\begin{array}{c}\text { Saikokeishito } \\
\text { Chai-Hu-Gui-Zhi-Tang }\end{array}$ & $\begin{array}{c}\text { Saikokaryukotsuboreito } \\
\text { Chai-Hu-Jia-Long-Gu-Mu-Li-Tang }\end{array}$ \\
\hline Bupleurum root & 7.0 & 6.0 & 7.0 & 5.0 & 5.0 \\
\hline Scutellaria root & 3.0 & 3.0 & 3.0 & 2.0 & 2.5 \\
\hline Pinellia tuber & 5.0 & 4.0 & 5.0 & 4.0 & 4.0 \\
\hline Jujube fruit & 3.0 & 3.0 & 3.0 & 2.0 & 2.5 \\
\hline Ginseng root & 3.0 & & 3.0 & 2.0 & 2.5 \\
\hline Ginger rhizome & 1.0 & 1.0 & 1.0 & 1.0 & 1.0 \\
\hline Glycyrrhiza root & 2.0 & & 2.0 & 2.0 & \\
\hline Cinnamon bark & & & 2.0 & 2.0 & 3.0 \\
\hline Peony root & & 3.0 & & 2.0 & \\
\hline Hoelen & & & 3.0 & & 3.0 \\
\hline Immature orange & & 2.0 & & & \\
\hline Rhubarb rhizome & & 1.0 & & & \\
\hline Alisma rhizome & & & 5.0 & & \\
\hline $\begin{array}{l}\text { Atractylodes lancea } \\
\text { rhizome }\end{array}$ & & & 3.0 & & \\
\hline Chuling & & & 3.0 & & \\
\hline Oyster shell & & & & & 2.5 \\
\hline Fossilized bone & & & & & 2.5 \\
\hline \multicolumn{6}{|l|}{ Percentage (w/w) } \\
\hline Scutellaria root & $12.5 \%$ & $13.0 \%$ & $7.5 \%$ & $9.1 \%$ & $8.8 \%$ \\
\hline Clinical indications & $\begin{array}{l}\text { Bronchial asthma, } \\
\text { common cold, } \\
\text { chronic liver } \\
\text { diseases, } \\
\text { enterogastritis }\end{array}$ & $\begin{array}{l}\text { Hyperlipidemia, } \\
\text { diabetes mellitus, } \\
\text { cholelithiasis, } \\
\text { jaundice }\end{array}$ & $\begin{array}{l}\text { Diarrhea, edema, } \\
\text { enterogastritis, } \\
\text { nephritic disease }\end{array}$ & $\begin{array}{l}\text { Duodenal ulcers, } \\
\text { pancreatitis, } \\
\text { chronic liver diseases }\end{array}$ & $\begin{array}{l}\text { Psychotropic stress, neurasthenia, } \\
\text { hypertension, atherosclerosis, } \\
\text { hypercholesterolemia }\end{array}$ \\
\hline
\end{tabular}

Signaling Technology), anti-phospho-Chk1 (pS301) rabbit polyclonal antibody and anti- $\beta$-actin antibody (Sigma-Aldrich) and secondary anti-IgG antibodies, as previously described (27). When necessary, membranes were stripped with Restore Western Blot Stripping Buffer (Pierce).

Immunofluorescence. Monolayers of cells were cultured for $48 \mathrm{~h}$ in 4-well cover glass chamber slides in medium containing $10 \%$ serum. Cells were washed twice in PBS supplemented with $1 \%$ bovine serum albumin (Sigma-Aldrich). The cell surface Fc receptor was blocked using IgG (Santa Cruz Biotechnology, Inc.) on ice for $15 \mathrm{~min}$. Cells were stained for $30 \mathrm{~min}$ at $37^{\circ} \mathrm{C}$ with 1:100 dilution of anti-CD44 FITC monoclonal antibody (BD Biosciences, Franklin Lakes, NJ, USA). After washing, cells were analyzed using Nikon Eclipse TS100-F with Nikon Intensilight C-HGFIE (Nikon Co., Ltd., Tochigi, Japan). Digital images were processed with NIS Elements BR3.2 imaging software (Nikon Co., Ltd.) and Adobe Photoshop 7.0 (San Jose, CA, USA).

Apoptosis analysis. HSC-3 or shCD44 HSC-3 cells ( $1 \times 10^{5}$ cells) were cultured on 12 -well plates for $24 \mathrm{~h}$ and treated with baicalin or baicalein for $24 \mathrm{~h}$. Cells were stained using the
FITC Annexin V Apoptosis detection kit I (BD Pharmingen) according to the manufacturer's instructions. Data acquisition and analysis were performed using the EC800 Flow Cytometry Analyzer (Sony Biotechnology, Tokyo, Japan) with EC800 analysis software (Sony Biotechnology). Annexin V-positive cells were considered as apoptotic cell death.

Statistical analysis. All quantitative data are presented as the mean \pm SD and were evaluated using one-way analysis of variance followed by Dunnett's multiple comparison. In all cases, $\mathrm{P}<0.05$ was considered statistically significant.

\section{Results}

Quantification of principle active constituents of Scutellaria root contents in five herbal medicines. We analyzed the half maximal inhibitory concentration $\left(\mathrm{IC}_{50}\right)$ of the five complete herbal medicines with human HNSCC cell lines (HSC-2 and HSC-3) and a human skin keratinocyte cell line (HaCaT), and the $\mathrm{IC}_{50}$ values ranged from 30.8 to $57.0 \mu \mathrm{g} / \mathrm{ml}$ (Table II). We next determined the components in representatives of five widely used herbal medicines containing Scutellaria root for evaluating potential anticancer effects. These medicinal 
Table II. Baicalin contents in extracts of each of five herbal medicines $(1 \mathrm{~g})$ and $\mathrm{IC}_{50}$ values $(\mu \mathrm{g} / \mathrm{ml})$ in HSC-2, HSC-3 and HaCaT cell lines.

\begin{tabular}{|c|c|c|c|c|}
\hline \multirow[b]{2}{*}{ Sample (Chinese name) } & \multirow[b]{2}{*}{ Baicalin contents $(\% \pm \mathrm{SD})$} & \multicolumn{3}{|c|}{$\mathrm{IC}_{50}(\mu \mathrm{g} / \mathrm{ml})$} \\
\hline & & HSC-2 & HSC-3 & $\mathrm{HaCaT}$ \\
\hline Shosaikoto (Xiao-Chai-Hu-Tang) & $5.1 \pm 0.3$ & $36.3 \pm 7.7$ & $44.6 \pm 6.1$ & $35.3 \pm 11$ \\
\hline Daisaikoto (Da-Chai-Hu-Tang) & $4.0 \pm 0.5$ & $37.2 \pm 4.0$ & $57.0 \pm 1.8$ & $40.4 \pm 7.1$ \\
\hline Saireito (Chai-Ling-Tang) & $3.5 \pm 0.6$ & $38.8 \pm 4.9$ & $47.1 \pm 7.5$ & $39.8 \pm 6.4$ \\
\hline Saikokeishito (Chai-Hu-Gui-Zhi-Tang) & $3.1 \pm 0.2$ & $41.2 \pm 5.2$ & $52.3 \pm 3.8$ & $30.8 \pm 5.1$ \\
\hline Saikokaryukotsuboreito (Chai-Hu-Jia-Long-Gu-Mu-Li-Tang) & $3.2 \pm 0.3$ & $37.4 \pm 6.6$ & $46.1 \pm 5.5$ & $33.7 \pm 4.4$ \\
\hline
\end{tabular}<smiles>O=c1cc(-c2ccccc2)oc2cc(OC3CCCCC3)c(O)c(O)c12</smiles>

Baicalin<smiles>O=c1cc(-c2ccccc2)oc2cc(O)c(O)c(O)c12</smiles>

Baicalein

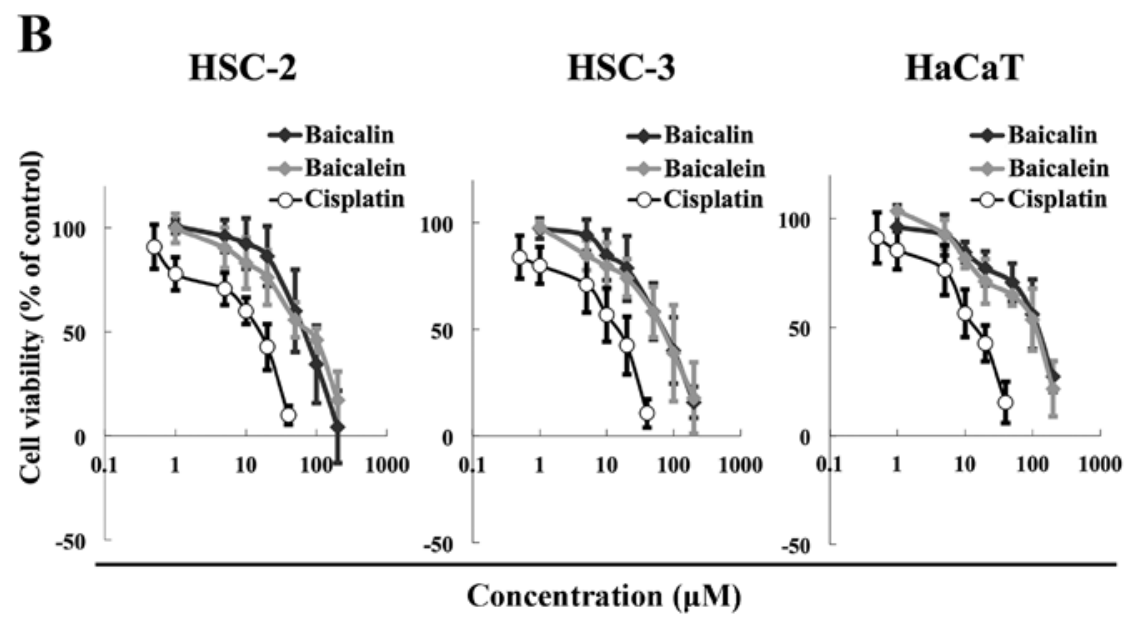

Figure 1. Effects of baicalin and baicalein on cell viability. (A) Chemical structures of baicalin and baicalein. Baicalein is the aglycone derivative of baicalin. (B) Cells were incubated with various concentrations of baicalin or baicalein for $72 \mathrm{~h}$ and cell viability was determined by MTT assays. Data are presented as the mean \pm standard deviation of at least three independent experiments.

herbs are formulated from several different herbs combined in a particular intrinsic mass ratio. Table I shows the clinical indications, composition of crude herbs, fixed proportions, and percentage (w/w) of Scutellaria root in hot water extracts of Shosaikoto, Daisaikoto, Saireito, Saikokeishito, and Saikokaryukotsuboreito. The Scutellaria root is a component of all of these five Chinese herbal medicines, and the percentage of Scutellaria root in these medicines ranged from 7.5 to $13.0 \%$.

Baicalin is one of the main constituents in Scutellaria root, and baicalein is its aglycone $(10,28)$. Table II shows the results of the quantitation of baicalin (5,6,7-trihydroxyflavone7-O-glucuronide) contents in each sample by HPLC-UV analysis. Standard curves for baicalin were linear $(r=0.999)$ over a concentration range of $10-250 \mu \mathrm{g} / \mathrm{ml}\left(\mathrm{t}_{\mathrm{R}} 10.3 \pm 0.15 \mathrm{~min}\right)$. Baicalein (5,6,7-trihydroxyflavone) $\left(t_{R} 20.5 \pm 0.28 \mathrm{~min}\right)$ was not detectable in any of the samples. All sample matrices contained a large number of constituents, of which baicalin (30-50 mg), comprising $\sim 3-5 \%(\mathrm{w} / \mathrm{w})$ of the total extract $(1 \mathrm{~g})$, was a common component. They were equivalent to $2-5 \mu \mathrm{M}$ content of baicalin in the five herbal medicines. These data show that the five herbal medicines contain a high proportion of baicalin (3-5\%). Baicalin is absorbed in the body, and it is metabolized to baicalein (28). Some studies have demonstrated that baicalin $(10,29)$ and baicalein (29-31) have potential anticancer activities. Therefore, we focused on these two ingredients to predict the effects of the five herbal medicines.

Baicalin and baicalein reduce HNSCC cell viability. The chemical structures of baicalin and baicalein are shown in Fig. 1A. The two flavones differ in that baicalein does not contain the glucuronic acid moiety at the $\mathrm{C} 7$ position on the 

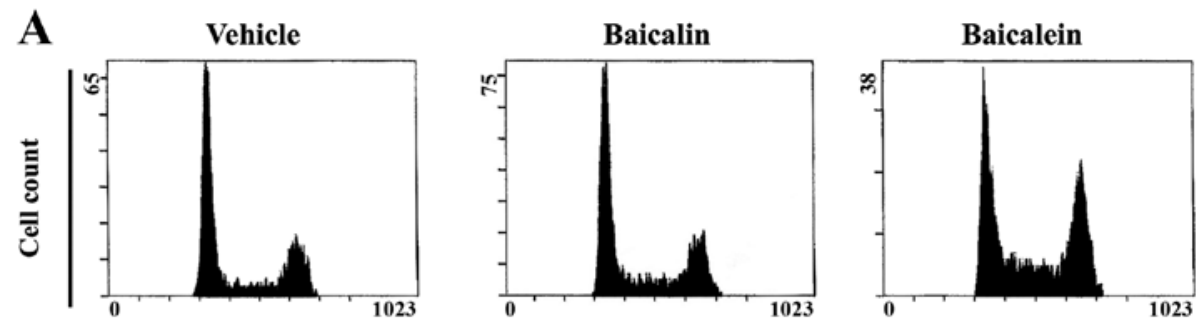

DNA content

B

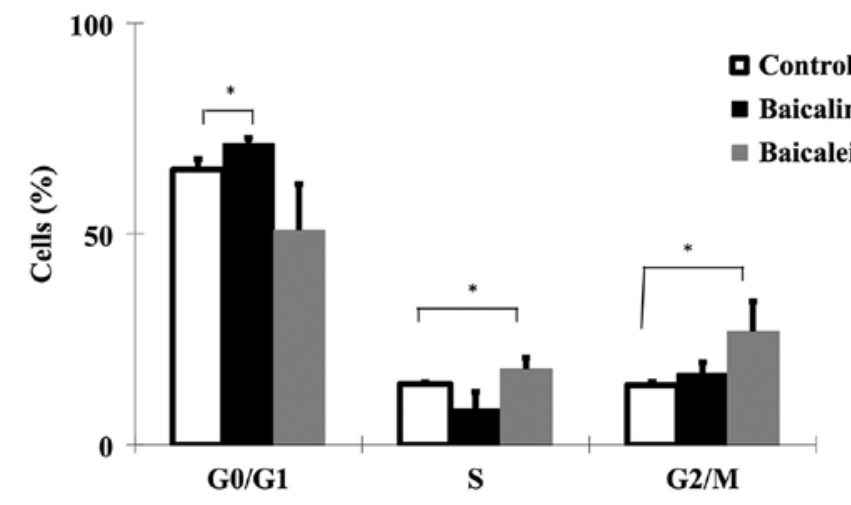

C

D
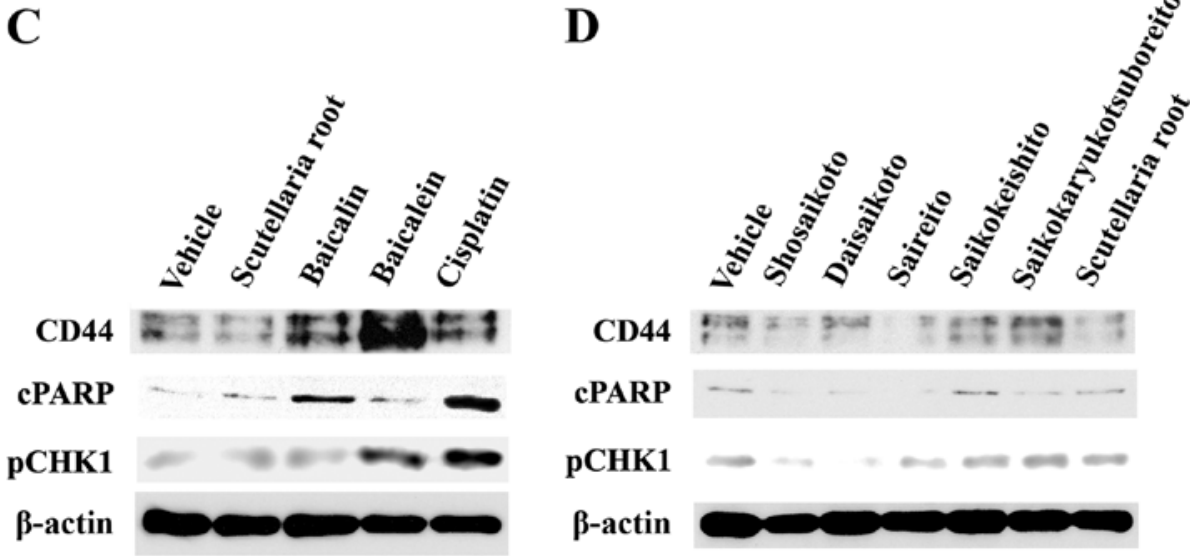

Figure 2. Effects of baicalin and baicalein on the cell cycle distribution of HSC-3 cells. (A) The cell cycle distribution of propidium iodide-stained HSC-3 cells was analyzed by flow cytometry at $48 \mathrm{~h}$ after treatment with baicalin or baicalein $(100 \mu \mathrm{M})$. Representative flow cytometry histograms illustrating the cell cycle distribution of HSC-3 cells. (B) Bar graphs showing the results of the cell cycle distribution. Data are presented as the mean \pm standard deviation $(\mathrm{n}=3)$. ${ }^{*} \mathrm{P}<0.05$, vs. control. (C) Immunoblot analysis of HSC-3 cells treated with dimethyl sulfoxide vehicle, baicalin $(100 \mu \mathrm{M})$, baicalein $(100 \mu \mathrm{M})$, cisplatin $(100 \mu \mathrm{M})$, Scutellaria root extract $(50 \mu \mathrm{g} / \mathrm{ml})$, or each of five herbal medicines $(50 \mu \mathrm{g} / \mathrm{ml})$ for $24 \mathrm{~h}$. $\beta$-actin was used as a loading control. (D) HSC-3 cells were treated with each of the five herbal medicines or Scutellaria root extract and subjected to immunoblot analysis.

flavone backbone. We next examined possible anticancer effects of baicalin and baicalein against HNSCC. The cytotoxicity of baicalin and baicalein in the HSC-2 and HSC-3 HNSCC cell lines and the HaCaT normal human keratinocyte cell line was evaluated by MTT assays. Both compounds reduced the viability of all three cell lines at concentrations ranging from 50 to $200 \mu \mathrm{M}$ for $72 \mathrm{~h}$ in a dose-dependent manner (Fig. 1B). The cytotoxicity of baicalin and baicalein was similar. Cisplatin was used as a positive control, a wellknown anticancer agent $(32,33)$. The $\mathrm{IC}_{50}$ values of baicalin were $54.3 \mu \mathrm{M}$ for HSC-2 cells, $60.6 \mu \mathrm{M}$ for HSC-3 cells, and $69.0 \mu \mathrm{M}$ for HaCaT cells. The corresponding $\mathrm{IC}_{50}$ values for baicalein were $60.7 \mu \mathrm{M}$ for HSC-2 cells, 58.4 $\mu \mathrm{M}$ for HSC-3 cells, and $64.5 \mu \mathrm{M}$ for $\mathrm{HaCaT}$ cells. Together our results show that baicalin and baicalein exhibit similar cytotoxic effects in HNSCC cells as cisplatin.

Baicalin and baicalein exert differential effects on the cell cycle. We next examined whether baicalin and baicalein affect the cell cycle progression of cancer cells. Based on cell viability results, baicalin and baicalein at concentrations of $100 \mu \mathrm{M}$ were used for subsequent analyses. Cell cycle distribution patterns were compared in control cells and cells treated for $48 \mathrm{~h}$ by flow cytometric analysis (Fig. 2A and B). While the majority of HSC-3 cells were in G0/G1 phase in the control group, only $6.1 \%$ of the cells were arrested in G0/G1 phase in response to baicalin, whereas $12.7 \%$ of cells were arrested in $\mathrm{G} 2 / \mathrm{M}$ phase in response to baicalein. Baicalein-induced G2/M phase arrest 
A

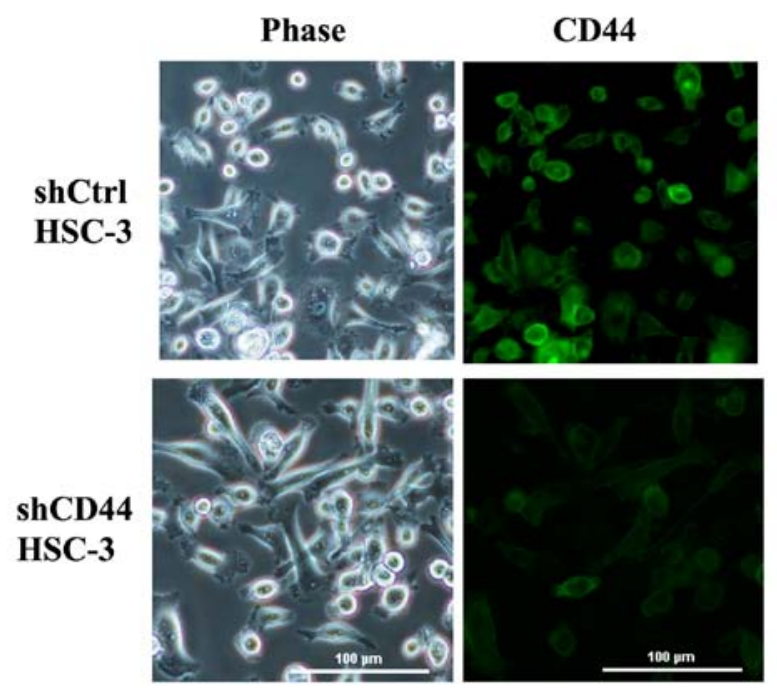

B

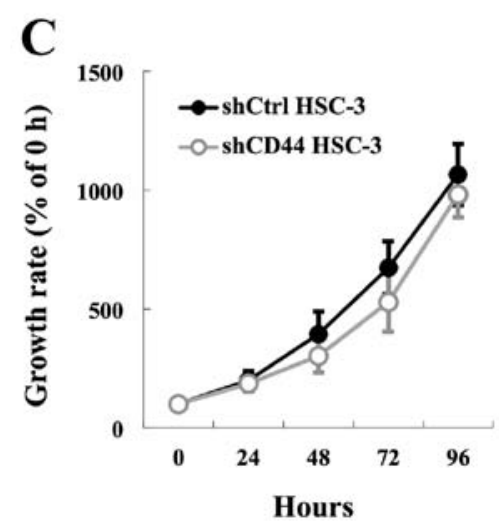

Figure 3. Comparison of CD44 expression between shCtrl HSC-3 and shCD44 HSC-3 cells. (A) Representative phase contrast (left panels) and anti-CD44 immunofluorescence images (right panels) of CD44 live cells are shown. Scale bar, $100 \mu \mathrm{m}$. (B) CD44 protein levels in shCtrl HSC-3 and shCD44 HSC-3 cells are shown by western blotting. (C) Cell growth curves from MTT assays performed in shCtrl HSC-3 and shCD44 HSC-3 cells.

was accompanied with a small increase $(3.4 \%)$ in $\mathrm{S}$ phase cells and a concomitant decrease in G0/G1 phase cells, suggesting that the $\mathrm{S}$ phase entry of the cells was not significantly affected in response to baicalein, but the exit from $\mathrm{S}$ phase might be partially impaired, causing a slight increase in $\mathrm{S}$ phase cells. Together our results showed that baicalin induces G0/G1 arrest and baicalein induces G2/M arrest in HSC-3 cells.

Baicalin and baicalein exert regulatory effects on CD44 expression and DNA damage response. We next explored the possible molecular responses associated with the G0/G1 and G2/M cell cycle arrest induced by baicalin and baicalein, respectively. We performed immunoblot analysis of the protein levels of cleaved PARP (cPARP) as an apoptosis marker, CD44 as a CSC surface marker, and phospho-Chk1 (S301) as a marker of DNA damage response to S-to-G2/M phase arrest in HSC-3 cells. Both flavones $(100 \mu \mathrm{M})$ increased the expression of CD44 after $48 \mathrm{~h}$ of treatment, but the effect of baicalein was more pronounced than that of baicalin (Fig. 2C). Baicalein-treated HSC-3 cells also showed lower levels of cPARP than baicalin-treated cells, suggesting that CD44 upregulation at G2/M phase may be an important mechanism for cell survival. We also investigated the DNA damage response upon treatment with these compounds. Baicalein and cisplatin induced phosphorylation of CHK1, as a marker of robust DNA damage response. Treatment with the five herbal medicines or Scutellaria root (all used at $50 \mu \mathrm{g} / \mathrm{ml}$ for $48 \mathrm{~h}$ ) did not significantly affect phosphorylation of CHK1 (Fig. 2D). These results demonstrate that HNSCC treated by baicalein can progressively escape apoptosis regardless of the induction of DNA damage response, and that this resistance phenomenon is correlated with inadequate expression of CD44. However, the protein levels of CD44, cPARP, and pCHK1 were not appreciably altered by any of the herbal medicines or by Scutellaria root.

Together, these studies suggest that baicalein-induced CD44 expression may cause apoptotic resistance, leading to $\mathrm{S}-\mathrm{to}-\mathrm{G} 2 / \mathrm{M}$ phase arrest regulated by the activation of the CHK1 pathway.

Generation of stable CD44-knockdown HSC-3 cells. Our above findings suggested that the CD44 upregulation may be correlated with resistance to apoptosis and DNA damage response at $\mathrm{G} 2 / \mathrm{M}$ arrest with activation of $\mathrm{CHK} 1$. Therefore, we generated HSC-3 cells with knockdown of CD44 to further investigate whether CD44 is involved in the proliferation and apoptotic resistance in HNSCC cells. HSC-3 transfected control (shCtrl HSC-3) and CD44 knockdown (shCD44 HSC-3) cell lines showed no significant morphological changes, such as the appearance of pseudopodia and spindle-shaped morphology (Fig. 3A). Immunostaining analyses for CD44 (Fig. 3A) corroborated the immunoblotting analysis (Fig. 3B), confirming downregulation of CD44 in the stable knockdown lines by $>95 \%$. Additionally, some previous observations have suggested that CD44 confers a decided growth advantage on certain types of cancer cells $(6,34)$; however, we observed no significant attenuation in growth rate in monolayer cultures of shCD44 HSC-3 cells compared with shCtrl HSC-3 cells after $96 \mathrm{~h}$ (Fig. 3C). These findings indicated that CD44 knockdown was not sufficient to mediate cell growth inhibition in this study.

Apoptotic resistance at $G 2 / M$ phase is reduced in CD44 knockdown HSC-3 cells. Our next step was to examine the 
A

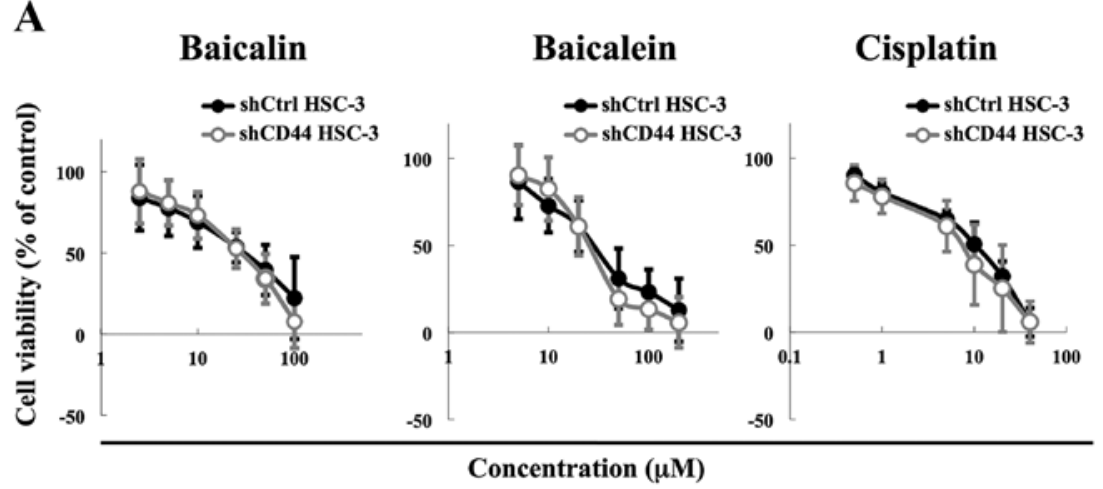

\section{B}

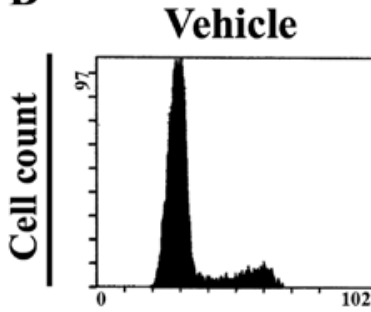

Baicalin

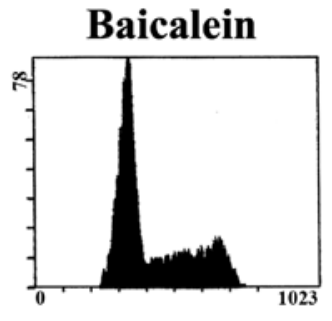

DNA content

C
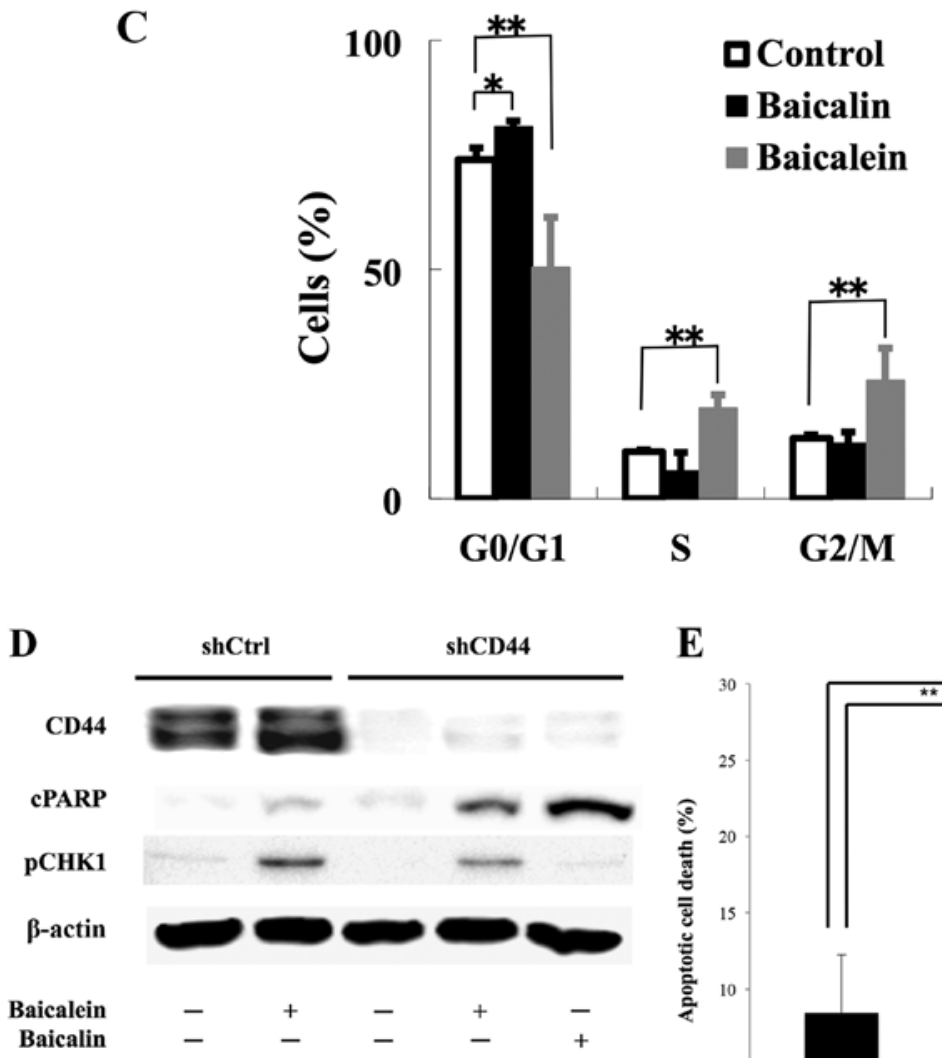

$\mathbf{E}$

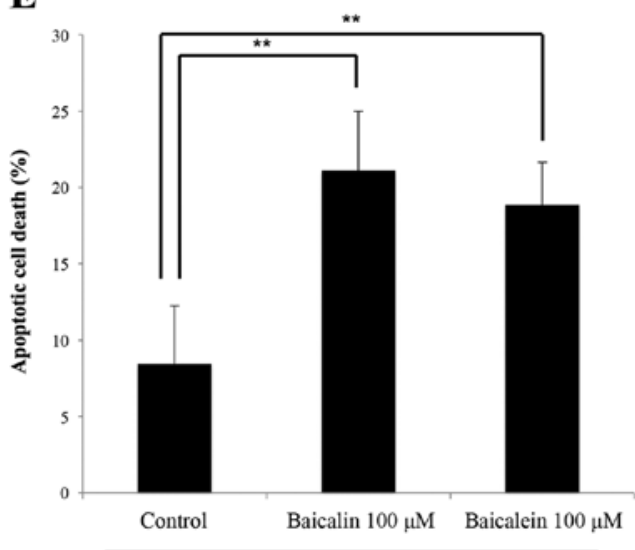

$\operatorname{shCD} 44$

Figure 4. Comparison of baicalein response between shCtrl HSC-3 and shCD44 HSC-3 cells. (A) Cell viability of shCtrl HSC-3 and shCD44 HSC-3 cells treated by baicalin, baicalein and cisplatin. (B) Representative cell cycle plots following treatment with baicalin and baicalein. (C) Cell cycle bar graphs showing the percentages of cells within the different cell cycle phases after treatment with baicalin and baicalein. Data represent mean \pm SD of three experiments, with each performed in duplicate. ${ }^{*} \mathrm{P}<0.05$, vs. control. ${ }^{* *} \mathrm{P}<0.01$, vs. control. (D) Immunoblot analysis of shCtrl HSC-3 and shCD44 HSC-3 cells following baicalin or baicalein treatment. (E) Flow cytometric analysis of apoptotic cell death in shCD44 HSC-3 cells. Bar graph indicates proportion of apoptotic cell death. ${ }^{*} \mathrm{P}<0.05$, vs. control. ${ }^{* *} \mathrm{P}<0.01$, vs. control. 
role of CD44 expression on apoptotic resistance by baicalein at $\mathrm{G} 2 / \mathrm{M}$ phase. We tested the ability of baicalein and baicalin to selectively kill shCD44 HSC-3 cells. Despite their CD44 knockdown phenotype, shCD44 HSC-3 cells did not show any significant differences in response to baicalein and baicalin compared with shCtrl HSC-3 cells (Fig. 4A). The $\mathrm{IC}_{50}$ values for baicalin were $43.7 \mu \mathrm{M}$ for shCtrl HSC-3 cells and $39.3 \mu \mathrm{M}$ for shCD44 HSC-3 cells. The corresponding $\mathrm{IC}_{50}$ values for baicalein were $59.6 \mu \mathrm{M}$ for shCtrl HSC-3 cells and $56.4 \mu \mathrm{M}$ for shCD44 HSC-3 cells.

To understand the role of CD44 in DNA damage response induction, we analyzed the effects of baicalin and baicalein treatments on the cell cycle progression and using immunoblotting. We found a similar trend in terms of effect of baicalin and baicalein on cell cycle progression and DNA damage response induction as compared with control cells (Figs. 2A, and B and 4B and C). Baicalein increased the number of cells in $\mathrm{S}$ phase by $9.5 \%$ and $\mathrm{G} 2 / \mathrm{M}$ phase by $12.6 \%$ compared with the vehicle control, while baicalin increased the number of cells in $\mathrm{G} 0 /$ G1 phase by $7.1 \%(\mathrm{P}<0.001)$ (Fig. 4C). Furthermore, baicalein enhanced cPARP, an apoptosis marker, in CD44 knockdown cells, while phosphorylation of CHK1, a marker of DNA damage response to S-to-G2/M phase arrest, was decreased by baicalein in CD44 knockdown cells (Fig. 4D). We also confirmed that baicalein enhanced apoptosis by Annexin V staining when CD44 was knocked down (Fig. 4E). These results suggest that CD44 is correlated with p-CHK1 expression and that CD44 expression plays a role in DNA damage response in HNSCC cells.

\section{Discussion}

In this study, we first examined whether traditional herbal medicines that contain Scutellaria root enhanced apoptosis of HNSCC cells. Our results showed that the five herbal medicines did not enhance apoptosis of HNSCC cells in cell culture experiments (Table II and Fig. 2D). We hypothesized that some ingredients of herbal medicine could inhibit the expression of CSC markers or enhance cancer cell apoptosis, thus we next examined whether ingredients of herbal medicine affected CD44 levels, as a cancer stem cell marker, or induced apoptosis. However, our findings showed that baicalin and baicalein, which are present in herbal medicine at high proportions, enhanced expression of CD44, and the cytostatic activities were similar to that of cisplatin in HNSCC cells. We next turned our attention to the potential induction of apoptosis by the two flavone compounds. Apoptosis is characterized by increased expression of cleaved PARP. PARP initiates multiple cellular responses, including DNA repair, cell cycle checkpoint control, apoptosis, and nuclear gene transcription (35), while cPARP is selectively involved in programmed cell death. Notably, baicalin increased cPARP level in HSC-3 cells, whereas baicalein did not, despite its induction of DNA damage response at $\mathrm{G} 2 / \mathrm{M}$ cell cycle arrest and inhibition of HSC-3 cell growth. In contrast, CD44 protein levels were markedly increased by baicalein, but not by baicalin. Therefore, we hypothesized that CD44 expression engaged with cPARP level and G2/M cell cycle arrest in the HSC-3 HNSCC cell line. We validated this hypothesis using CD44-knockdown HSC-3 cells. We found that cPARP level, as an apoptotic response marker, was significantly increased by CD44 knockdown at $\mathrm{G} 2 / \mathrm{M}$ phase initiating the DNA damage response. These results demonstrated that inadequate expression of CD44 has a role in the transient apoptotic resistance to the DNA damage response.

HNSCC tumors contain a subpopulation of CSCs that are distinguished by a high level of CD44 expression (4). CSCs are illustrious for their resistance to DNA damage and high DNA repair capacity (3), and $C D 44^{\text {high }}$ cells are less sensitive to apoptosis-inducing agents than $\mathrm{CD} 44^{\text {low }}$ cells. CD $44^{\text {high }}$ cells in HNSCC tumors also spend a consistently longer amount of time in $\mathrm{G} 2$ phase than $\mathrm{CD} 44^{\text {low }}$ cells (7). Furthermore, the proportion of $\mathrm{CD}_{4} 4^{+}$cells relative to $\mathrm{CD} 44^{-}$cells in $\mathrm{G} 2$ phase is markedly increased by treatment with certain apoptosis-inducing stimuli (6). Our data demonstrated that baicalein-mediated upregulation of CD44 was linked to an extended G2/M phase in HNSCC cells and a possible maintenance of the stemness to a CSC-like phenotype, potentially providing cells with the opportunity and capacity to repair DNA damage. We propose that the metabolism of baicalin to baicalein, followed by the upregulation of CD44, might be involved in aberrant repair of damaged cells to enable their survival, potentially contributing to apoptotic resistance in HNSCC tumors. These results suggest that, although both molecular structures of baicalin and baicalein appear similar, the cellular environment to DNA damage response may differ by CD44 upregulation, especially cell cycle progression, explaining their differential apoptotic threshold to DNA damage repair.

It is important to emphasize that the five herbal medicines and Scutellaria root extract had no clear effect on the levels of CD44, cPARP or DNA damage response. It is possible that the cell cycle stage at the time of drug treatment or some other as yet unknown mechanism might modulate the switch between cell death and survival in HNSCC-derived CSCs.

Together our results indicate that baicalin/baicalein may potentially induce CD44 upregulation to initiate the stemness of HNSCCs. Moreover, upregulated CD44 may render the stem cells resistant to programmed cell death, perhaps through $\mathrm{G} 2 / \mathrm{M}$ arrest. The potential induction of CD44 expression may be partly responsible for resistance to DNA-damaging treatments.

Our results showed that baicalein could significantly induce cell cycle arrest at G2/M phase and increased level of cleaved PARP-1 (an apoptotic marker) in CD44 knockdown cells without altering growth inhibitory effect and cell cycle distribution. This indicates that transient expression of CD44 could enhance DNA repair damage response and contribute to survival ability by apoptotic resistance by baicalein in HSC-3 cells.

In conclusion, knockdown and functional evaluation of CD44, a cell surface marker of cancer stem-like cells, suggested that induction of CD44 by baicalein, as an herbal ingredient, is involved, at least in part, in an initial survival advantage, resulting in efficient DNA damage repair. Overexpression of CD44 provides relative protection of HNSCC cells in terms of cell death responses, but it is unclear whether the rescued cells convert DNA damage to mutations and/or translocations during treatment of cancer. However, the present study indicated that the function of CD44 as a CSC marker of HNSCC is involved in the DNA damage response in G2/M arrest. 


\section{Acknowledgements}

This study was supported in part by JSPS KAKENHI (grant nos. 24791982, 26462854 and 26861748).

\section{References}

1. Magee JA, Piskounova E and Morrison SJ: Cancer stem cells: Impact, heterogeneity, and uncertainty. Cancer Cell 21: 283-296, 2012.

2. Visvader JE and Lindeman GJ: Cancer stem cells: Current status and evolving complexities. Cell Stem Cell 10: 717-728, 2012.

3. Bao S, Wu Q, McLendon RE, Hao Y, Shi Q, Hjelmeland AB Dewhirst MW, Bigner DD and Rich JN: Glioma stem cells promote radioresistance by preferential activation of the DNA damage response. Nature 444: 756-760, 2006.

4. Prince ME, Sivanandan R, Kaczorowski A, Wolf GT, Kaplan MJ, Dalerba P, Weissman IL, Clarke MF and Ailles LE: Identification of a subpopulation of cells with cancer stem cell properties in head and neck squamous cell carcinoma. Proc Natl Acad Sci USA 104: 973-978, 2007.

5. Zöller M: CD44: Can a cancer-initiating cell profit from an abundantly expressed molecule? Nat Rev Cancer 11: 254-267, 2011.

6. Chikamatsu K, Ishii H, Takahashi G, Okamoto A, Moriyama M, Sakakura K and Masuyama K: Resistance to apoptosis-inducing stimuli in CD44 ${ }^{+}$head and neck squamous cell carcinoma cells Head Neck 34: 336-343, 2012.

7. Harper LJ, Costea DE, Gammon L, Fazil B, Biddle A and Mackenzie IC: Normal and malignant epithelial cells with stem-like properties have an extended G2 cell cycle phase that is associated with apoptotic resistance. BMC Cancer 10: 166 2010.

8. Joshua B, Kaplan MJ, Doweck I, Pai R, Weissman IL, Prince ME and Ailles LE: Frequency of cells expressing CD44, a head and neck cancer stem cell marker: Correlation with tumor aggressiveness. Head Neck 34: 42-49, 2012.

9. Orian-Rousseau V: CD44, a therapeutic target for metastasising tumours. Eur J Cancer 46: 1271-1277, 2010.

10. Li-Weber M: New therapeutic aspects of flavones: The anticancer properties of Scutellaria and its main active constituents Wogonin, Baicalein and Baicalin. Cancer Treat Rev 35: 57-68, 2009.

11. Zha LH, He LS, Lian FM, Zhen Z, Ji HY, Xu LP and Tong XL: Clinical strategy for optimal traditional Chinese medicine (TCM) herbal dose selection in disease therapeutics: Expert consensus on classic TCM herbal formula dose conversion. Am J Chin Med 43: 1515-1524, 2015.

12. Peng H, He Y, Zheng G, Zhang W, Yao Z and Xie W: Metaanalysis of traditional herbal medicine in the treatment of nonalcoholic fatty liver disease. Cell Mol Biol (Noisy-le-grand) 62: 88-95, 2016

13. Sumino M, Saito Y, Ikegami F, Hirasaki Y and Namiki T: Extraction efficiency of shosaikoto (xiaochaihu tang) and investigation of the major constituents in the residual crude drugs. Evid Based Complement Alternat Med 2012: 890524, 2012

14. He JX, Ohno K, Tang J, Hattori M, Tani T and Akao T: Da-Chaihu-Tang alters the pharmacokinetics of nifedipine in rats and a treatment regimen to avoid this. J Pharm Pharmacol 66: 1623-1630, 2014

15. Kato S, Hayashi S, Kitahara Y, Nagasawa K, Aono H, Shibata J, Utsumi D, Amagase K and Kadowaki M: Saireito (TJ-114), a Japanese traditional herbal medicine, reduces 5-fluorouracilinduced intestinal mucositis in mice by inhibiting cytokine-mediated apoptosis in intestinal crypt cells. PLoS One 10: e0116213, 2015.

16. Su SB, Xie MJ, Sawabu N and Motoo Y: Suppressive effect of herbal medicine saikokeishito on acinar cell apoptosis in rat spontaneous chronic pancreatitis. Pancreatology 7: 28-36, 2007.

17. Iijima H, Daikonya A, Takamatsu S, Kanno A, Magariyama K, Yoshikawa K, Takamiya T, Ueda Y, Yakubo S, Matsumoto T, et al: Effects of the herbal medicine composition 'Saiko-karyukotsu-borei-To' on the function of endothelial progenitor cells in hypertensive rats. Phytomedicine 20: 196-201, 2013.
18. Nakayama T, Suzuki S, Kudo H, Sassa S, Nomura M and Sakamoto S: Effects of three Chinese herbal medicines on plasma and liver lipids in mice fed a high-fat diet. J Ethnopharmacol 109: 236-240, 2007.

19. Ben-Arye E, Mahajna J, Aly R, Ali-Shtayeh MS, Bentur Y, Lev E, Deng $G$ and Samuels N: Exploring an herbal 'wonder cure' for cancer: A multidisciplinary approach. J Cancer Res Clin Oncol 142: 1499-1508, 2016.

20. Chung VC, Wu X, Lu P, Hui EP, Zhang Y, Zhang AL, Lau AY, Zhao J, Fan M, Ziea ET, et al: Chinese herbal medicine for symptom management in cancer palliative care: Systematic review and meta-analysis. Medicine (Baltimore) 95: e2793, 2016.

21. Ohtake N, Nakai Y, Yamamoto M, Sakakibara I, Takeda S, Amagaya S and Aburada M: Separation and isolation methods for analysis of the active principles of Sho-saiko-to (SST) oriental medicine. J Chromatogr B Analyt Technol Biomed Life Sci 812: 135-148, 2004.

22. Yoshie F, Iizuka A, Komatsu Y, Matsumoto A, Itakura $\mathrm{H}$ and Kondo K: Effects of Dai-saiko-to (Da-Chai-Hu-Tang) on plasma lipids and atherosclerotic lesions in female heterozygous heritable Kurosawa and Kusanagi-hypercholesterolemic (KHC) rabbits. Pharmacol Res 50: 223-230, 2004.

23. Kishida Y, Miki H, Nishii T, Inoue T, Nishida S, Yoshikawa $H$ and Sugano N: Therapeutic effects of Saireito (TJ-114), a traditional Japanese herbal medicine, on postoperative edema and inflammation after total hip arthroplasty. Phytomedicine 14: 581-586, 2007.

24. Ohta Y, Kongo-Nishimura M, Hayashi T, Kitagawa A, Matsura T and Yamada K: Saikokeishito extract exerts a therapeutic effect on $\alpha$-naphthylisothiocyanate-induced liver injury in rats through atenuation of enhanced neutrophil infiltration and oxidative stress in the liver tissue. J Clin Biochem Nutr 40: 31-41, 2007

25. Yoshie F, Iizuka A, Kubo M, Komatsu Y, Matsumoto A, Itakura $\mathrm{H}$, Takeda $\mathrm{H}$, Matsumiya $\mathrm{T}$ and Kondo K: Protective effects of Saiko-ka-ryukotsu-borei-to (Chai-Hu-Jia-Long$\mathrm{Gu}-\mathrm{Mu}-\mathrm{Li}$-Tang) against atherosclerosis in Kurosawa and Kusanagi-hypercholesterolemic (KHC) rabbits. Pharmacol Res 43: 481-488, 2001

26. Ohkoshi E, Nagashima T, Sato H, Fujii Y, Nozawa K and Nagai M: Simple preparation of baicalin from Scutellariae Radix. J Chromatogr A 1216: 2192-2194, 2009.

27. Umemura N, Zhu J, Mburu YK, Forero A, Hsieh PN, Muthuswamy R, Kalinski P, Ferris RL and Sarkar SN: Defective $\mathrm{NF}-\kappa \mathrm{B}$ signaling in metastatic head and neck cancer cells leads to enhanced apoptosis by double-stranded RNA. Cancer Res 72: 45-55, 2012.

28. Trinh HT, Joh EH, Kwak HY, Baek NI and Kim DH: Anti-pruritic effect of baicalin and its metabolites, baicalein and oroxylin A, in mice. Acta Pharmacol Sin 31: 718-724, 2010.

29. Takahashi H, Chen MC, Pham H, Angst E, King JC, Park J, Brovman EY, Ishiguro H, Harris DM, Reber HA, et al: Baicalein, a component of Scutellaria baicalensis, induces apoptosis by Mcl-1 down-regulation in human pancreatic cancer cells. Biochim Biophys Acta 1813: 1465-1474, 2011.

30. Donald G, Hertzer K and Eibl G: Baicalein - an intriguing therapeutic phytochemical in pancreatic cancer. Curr Drug Targets 13: 1772-1776, 2012.

31. Naveenkumar C, Asokkumar S, Raghunandhakumar S, Jagan S, Anandakumar P, Augustine TA, Kamaraj S and Devaki T: Potent antitumor and antineoplastic efficacy of baicalein on benzo(a) pyrene-induced experimental pulmonary tumorigenesis. Fundam Clin Pharmacol 26: 259-270, 2012.

32. Weiss JM, Bagley S, Hwang WT, Bauml J, Olson JG, Cohen RB, Hayes DN and Langer C: Capecitabine and lapatinib for the firstline treatment of metastatic/recurrent head and neck squamous cell carcinoma. Cancer 122: 2350-2355, 2016.

33. Kurokawa M, Ise N, Omi K, Goishi K and Higashiyama S: Cisplatin influences acquisition of resistance to moleculartargeted agents through epithelial-mesenchymal transition-like changes. Cancer Sci 104: 904-911, 2013

34. Chappell J and Dalton S: Altered cell cycle regulation helps stem-like carcinoma cells resist apoptosis. BMC Biol 8: 63, 2010.

35. Schreiber V, Dantzer F, Ame JC and de Murcia G: Poly(ADPribose): Novel functions for an old molecule.Nat Rev Mol Cell Biol 7: 517-528, 2006. 